\title{
Pathotyping of Newcastle disease virus with a filamentous bacteriophage
}

\author{
Priadarishni Ramanujam ${ }^{1}$, Wen Siang $\operatorname{Tan}^{1}$, Sheila Nathan ${ }^{2}$, and Khatijah Yusoff ${ }^{1}$
}

BioTechniques 36:296-302 (February 2004)

\begin{abstract}
A filamentous phage bearing the peptide sequence TLTTKLY was isolated from a heptapeptide phage display library against a velogenic Newcastle disease virus (NDV). In order to investigate the potential of this specific phage as an immunological reagent in virus pathotyping, an enzyme-linked immunosorbent assay (ELISA)-based method was developed. This method can differentiate the velogenic strains from the mesogenic and lentogenic strains. An equilibrium-binding assay in solution showed that the interactions between the phage and all the NDV strains gave rise to two widely differing dissociation constants $\left(K_{\mathrm{d}}{ }^{\mathrm{rel}}\right)$. Based upon the first $K_{\mathrm{d}}{ }^{\mathrm{rel}}$ values, NDV strains can be classified into two groups; the first comprises the velogenic strains, and the second consists of the mesogenic and lentogenic strains. These results indicate a high degree of correlation between the binding affinities and pathotyping of NDV strains using the TLTTKLY phage.
\end{abstract}

\section{INTRODUCTION}

The ability to attach and penetrate a host cell is one of the major factors that determine the pathogenicity of a virus. These activities are usually mediated by proteins or glycoproteins located on the surface of the virus. For instance, the Newcastle disease virus (NDV), a member of Paramyxoviridae, has three pathotypes: (i) velogenic (highly virulent), (ii) mesogenic (moderately virulent), and (iii) lentogenic (avirulent) (1). The molecular determinant of its virulence is dependent on the two surface glycoproteins, hemagglutininneuraminidase $(\mathrm{HN})$ and fusion $(\mathrm{F})$ (2). The HN glycoprotein possesses hemagglutination (HA) and neuraminidase (NA) activities, with the avirulent strains having slightly longer $\mathrm{C}$ termini than those of the virulent strains (2). However, the transition point at which additional C-terminal extension of the $\mathrm{HN}$ protein causes diminution in virulence has not been determined. The $\mathrm{F}$ protein participates in the fusion activity of the virus (3). It is synthesized as a precursor, $\mathrm{F}_{\mathrm{o}}$, which needs to be cleaved into $F_{1}$ and $F_{2}$ for activation. The nature of cleavage sites correlates with virulence of the virus. Those strains with multiple-basic residues in the $\mathrm{F}_{\mathrm{o}}$ cleavage site are virulent strains, whereas those strains with a single basic residue are avirulent (2).

It is of primary importance to be able to differentiate the various pathotypes, but current diagnostic methods are inadequate for early identification of NDV during outbreaks. Conventional methods used for pathotyping of NDV are mean death time (MDT), intracerebral pathogenicity index (ICPI), and intravenous pathogenicity index (IVPI) (1). With the evolution in molecular techniques, several reliable methods for pathotyping have emerged. Numerous systems target the cleavage site of the $\mathrm{F}$ protein as its core pathotyping target, and many of these methods use the reverse transcription PCR (RTPCR) technique followed by restriction enzyme (RE) digestion (4) or nucleotide sequencing $(5,6)$. Recently, an RTPCR was developed to screen and differentiate virulent from avirulent NDV isolates using three sets of primers specific for amplifying $\mathrm{F}$ protein genespecific RNA from virulent, avirulent, or all isolates, respectively (7). Fluorogenic probes designed to recognize the nucleotide sequence at the cleavage site of the $\mathrm{F}$ gene were also utilized in a modified TaqMan ${ }^{\circledR}$ detection system (Applied Biosystems, Foster City, CA, USA) to distinguish NDV strains (8). Antipeptide antibodies targeted at $\mathrm{F}_{0}$ and $\mathrm{HN}_{\mathrm{o}}$ activation sites $(9,10)$ and also against the $\mathrm{C}$ termini of the $\mathrm{F}_{2}$ polypeptides and $\mathrm{C}$-terminal extension of the $\mathrm{HN}_{\mathrm{o}}$ sites (11) were produced for the intention of NDV pathotyping.

As a model system for virus pathotyping using specific bacteriophage, we employed a fusion phage carrying the TLTTKLY sequence previously selected from a phage display library (12) to determine its binding affinities to various NDV strains and developed an enzyme-linked immunosorbent assay (ELISA)-based method to differentiate these NDV pathotypes.

\section{MATERIALS AND METHODS}

\section{Propagation and Purification of NDV}

Propagation and purification of NDV strains were as previously described (13). The velogenic strains used in this study were AF2240, 00/IKS, 01/

\footnotetext{
${ }^{1}$ Universiti Putra Malaysia and ${ }^{2}$ Universiti Kebangsaan Malaysia, Selangor, Malaysia
} 
TM, 01/C, and 3410/92 P2. Mesogens comprised 2641/91 P2, 5953/89 P3, and 6385/90 P3 strains, while the lentogenic strains were V4 Que, F, 8820/92 P3, and 1266/89 P3. The pathotypes of these strains have previously been determined by nucleotide sequence analysis of the F cleavage site: AF2240 (14), strains 00/IKS, 01/TM, and 01/ C (S.W. Tan, personal communication), 3410/92 P2, 6385/90 P3, and F (C.L. Kho, personal communication), V4 Que (13), and 2641/91 P2, 5953/89 P3, 8820/92 P3, and 1266/91 P2 (15). The protein concentration of the purified virus was measured using the Bradford assay (16) and hemagglutination units (HAU) of the unpurified virus were determined as previously described (17). One HAU in the hemagglutinin titration is the minimum amount of virus that will cause complete agglutination of the red blood cells.

\section{Large-Scale Propagation, Purifica- tion, and Titration of Fusion Phage}

Methods used were as previously described (12).

\section{$\mathrm{K}_{d}{ }^{\text {rel }}$ Determination}

Varying concentrations of various NDV strains (0.001-10 nM; $120 \mu \mathrm{L}$ ) and a constant phage concentration $\left[10^{10}\right.$ plaque forming units (pfu); $100 \mu \mathrm{L}$ ) were incubated in a microfuge tube for $20 \mathrm{~h}$ at $25^{\circ} \mathrm{C}$. A portion of the incubation mixtures $(100 \mu \mathrm{L})$ was carefully transferred into wells that had been coated with the corresponding NDV strain $(20 \mu \mathrm{g} / \mathrm{mL}, 100 \mu \mathrm{L}$; with $\mathrm{Na}_{2} \mathrm{CO}_{3} / \mathrm{NaHCO}_{3}$ buffer, $\mathrm{pH}$ 9.6) and blocked $[0.1 \%$ bovine serum albumen (BSA) w/v in Tris-buffered saline (TBS); $120 \mu \mathrm{L}$ ], to allow unbound phages in solution to interact with the immobilized NDV. After incubation for $1 \mathrm{~h}$ at $25^{\circ} \mathrm{C}$, the wells were washed with TBS containing $0.5 \%$ Tween ${ }^{\circledR} 20$ (TBST), and bound phages were eluted and titered as described (18). A plot representing percentage of free phage versus NDV concentration was prepared, and a curve was fitted to these points using equations for two binding sites (GraFit ${ }^{\mathrm{TM}}$ version 3.0; Erithacus Software Ltd., Surrey, UK).

\section{Pathotype Detection with TLTTKLY Phage}

A series of different concentrations (2-50 HAU; $100 \mu \mathrm{L}$ ) of unpurified
NDV strains from allantoic fluid was coated on microtiter plate wells. The wells were washed and blocked as described above. The wells were washed again, and the TLTTKLY phage $\left(10^{10}\right.$ $\mathrm{pfu} / \mathrm{mL} ; 100 \mu \mathrm{L})$ was added and incubated at $25^{\circ} \mathrm{C}$ for $1 \mathrm{~h}$. This was followed by another wash and the

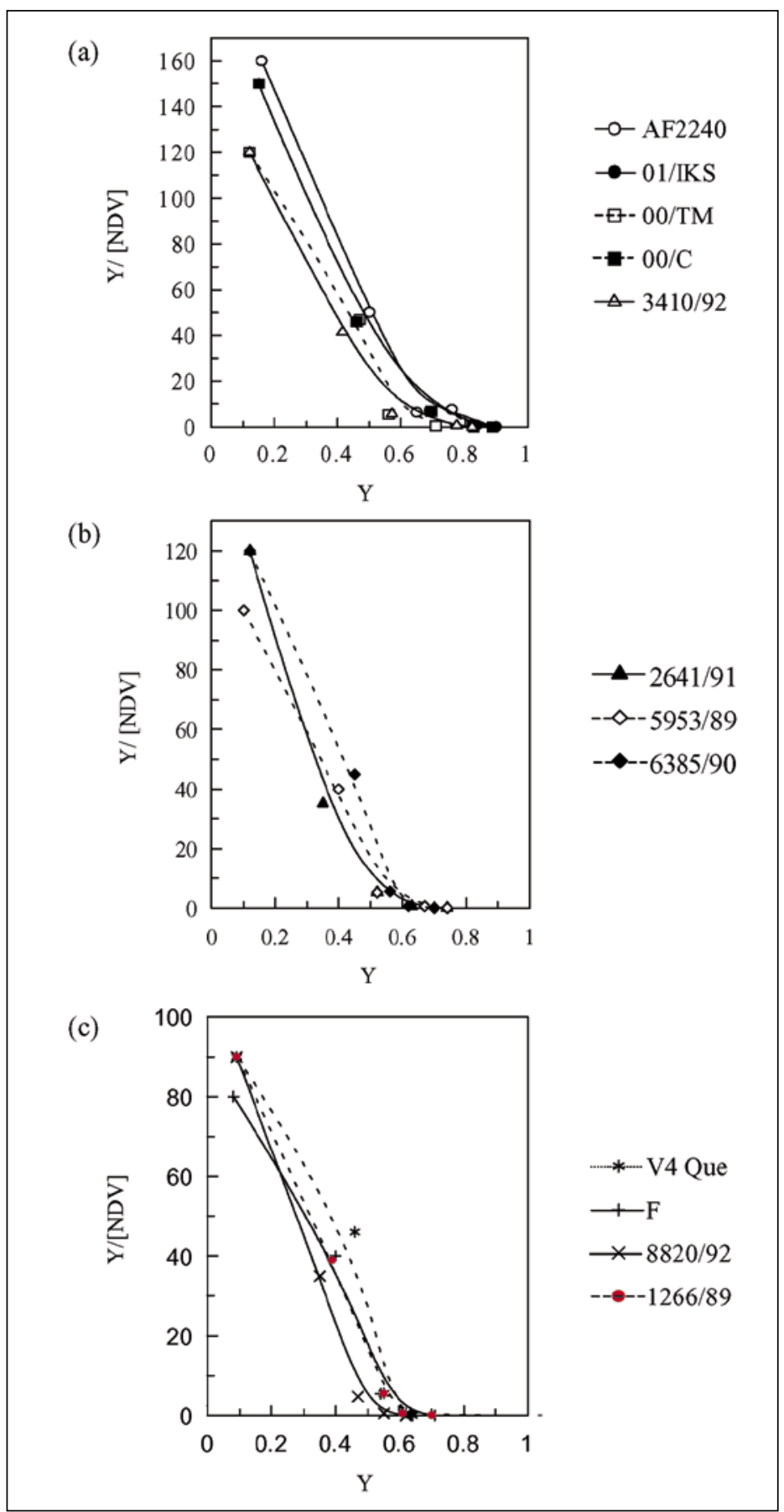

Figure 1. Scatchard plots for the binding of TLTTKLY phage to different NDV strains. (a) Velogenic strains, (b) mesogenic strains, and (c) lentogenic strains. NDV, Newcastle disease virus. 
addition of horseradish peroxidase (HRP)-conjugated anti-M13 antibodies (100 $\mu \mathrm{L}$; Amersham Biosciences, Little Chalfont, Buckinghamshire, UK) and incubated for $1 \mathrm{~h}$ at $25^{\circ} \mathrm{C}$. After washing, ABTS substrate [2,2'-azino-bis(3ethylbenzthiazoline-6-sulfonic acid); $100 \mu \mathrm{L}$; Roche Diagnostics GmbH, Mannheim, Germany] was added and incubated for $30 \mathrm{~min}$ at $25^{\circ} \mathrm{C}$. The absorbance was measured at $415 \mathrm{~nm}$.

\section{RESULTS}

\section{$\mathbf{K}_{d}^{\text {rel }}$ Determination}

The binding data collected for the interaction between the phage and NDV strains were first analyzed with the Scatchard plot to determine whether the phage has one or more binding sites. The graphs plotted (Figure 1) were Y/ [NDV] versus $Y$, where fraction bound,
$\mathrm{Y}=\left[\mathrm{pfu}_{0}-\mathrm{pfu}\right] / \mathrm{pfu}_{0}$. pfu is the free phage at different NDV concentration, and $\mathrm{pfu}_{0}$ is the free phage when [NDV] $=0$. The Scatchard plots gave rise to a concave shape for all the strains, suggesting that there are two binding sites between the phage and NDV strains. To avoid misinterpretation of nonlinear Scatchard plots, a nonlinear fitting of the binding data with the two binding site equation was employed. All the

Table 1. $K_{d}{ }^{\text {rel }}$ Values Obtained for Different NDV Strains with TLTTKLY Phage

(a)

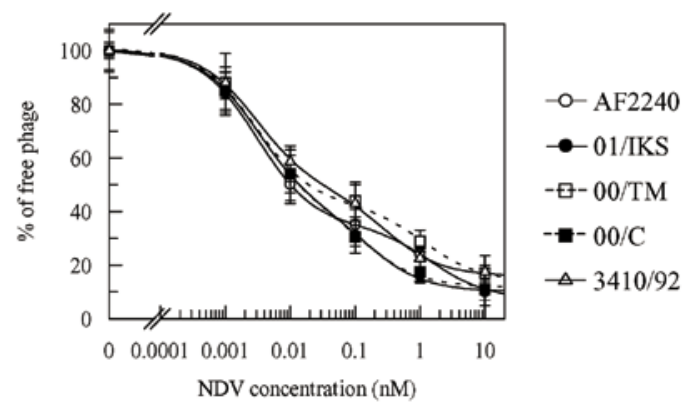

(b)

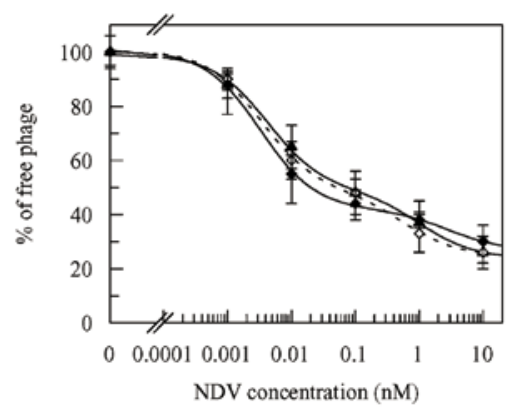

(c)

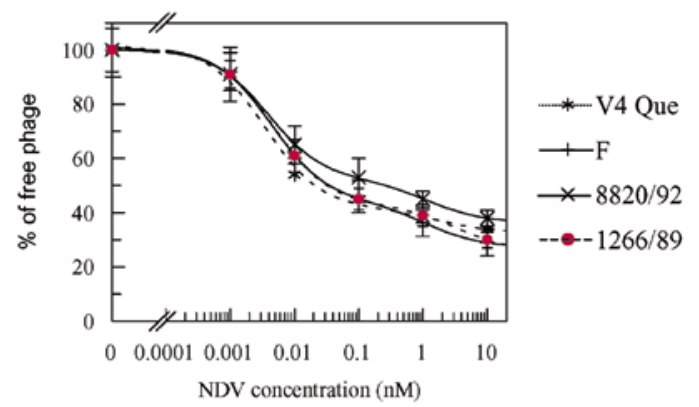

Figure 2. Semilogarithmic representation of the binding of the TLTTKLY phage to different NDV strains with two different affinities. (a) Velogenic, (b) mesogenic, and (c) lentogenic NDV strains. Assays were performed in triplicates and the error bars represent the standard deviation of the mean $(\overline{\times} \pm \mathrm{SD})$. NDV, Newcastle disease virus.

\begin{tabular}{|llll|}
\hline NDV Strains & Pathotype & $\begin{array}{l}\mathbf{K}_{\boldsymbol{d} 1} \text { rel } \\
(\mathbf{p M})\end{array}$ & $\begin{array}{l}\mathbf{K}_{\boldsymbol{d} 2} \text { rel } \\
(\mathbf{n M})\end{array}$ \\
\hline AF2240 & Velogenic & $2.8 \pm 0.0$ & $1.40 \pm 0.01$ \\
00/IKS & Velogenic & $2.4 \pm 0.4$ & $0.14 \pm 0.07$ \\
01/TM & Velogenic & $2.6 \pm 0.2$ & $1.11 \pm 0.11$ \\
01/C & Velogenic & $2.4 \pm 0.3$ & $0.12 \pm 0.05$ \\
3410/92 P2 & Velogenic & $2.6 \pm 0.1$ & $0.28 \pm 0.12$ \\
2641/91 P2 & Mesogenic & $3.9 \pm 0.1$ & $0.98 \pm 0.54$ \\
5953/89 P3 & Mesogenic & $3.3 \pm 0.1$ & $0.56 \pm 0.33$ \\
6385/90 P3 & Mesogenic & $3.3 \pm 0.2$ & $2.60 \pm 0.12$ \\
V4 Que & Lentogenic & $3.5 \pm 0.2$ & $1.50 \pm 0.45$ \\
F & Lentogenic & $4.1 \pm 0.1$ & $1.15 \pm 0.64$ \\
8820/92 P3 & Lentogenic & $3.6 \pm 0.3$ & $1.12 \pm 0.49$ \\
1266/89 P3 & Lentogenic & $4.5 \pm 0.4$ & $3.00 \pm 1.00$ \\
Values represent the mean $(\bar{x} \pm$ SD) of triplicate determination. \\
\hline
\end{tabular}

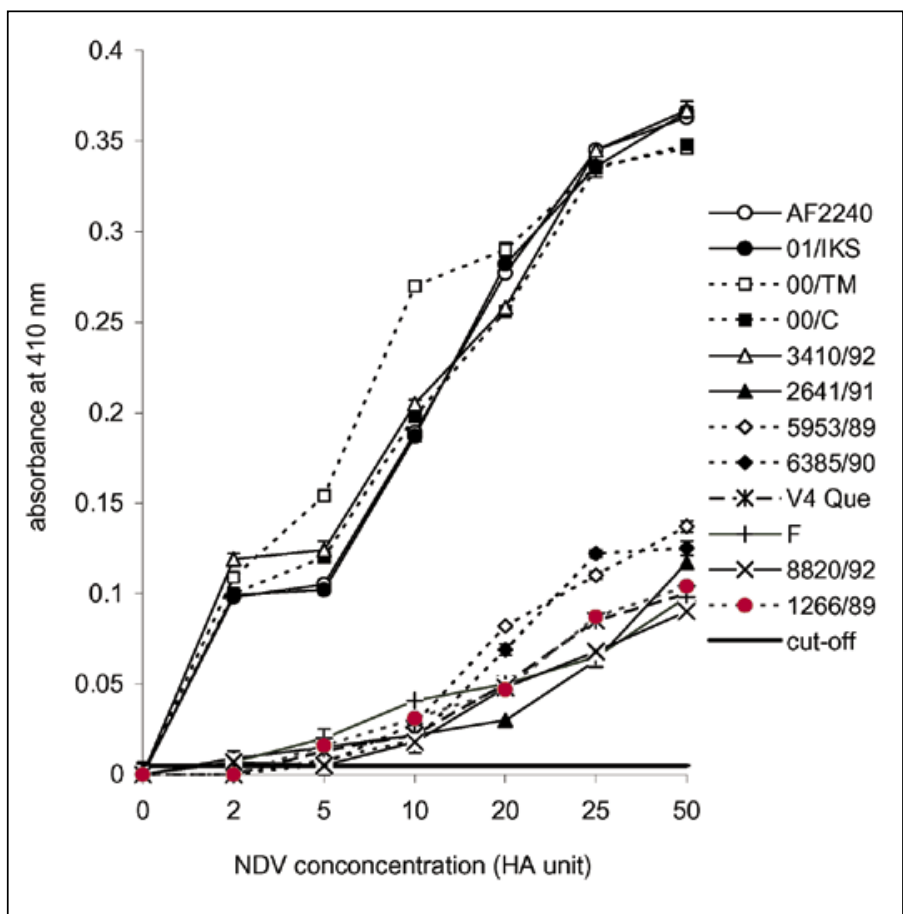

Figure 3. Detection of NDV pathotypes. The straight black line across the graph is the cut-off value. Any values above this are considered positive, and values below this are considered negative. The cut-off value is calculated as the mean value of the negative control plus $3 \mathrm{SD}$. The experiment was carried out in triplicate, and error bars represent the standard deviation of the mean $(\bar{x} \pm \mathrm{SD})$. NDV, Newcastle disease virus. 
binding data fit well with the two binding site equation (Figure 2), suggesting the TLTTKLY phage displayed two different binding affinities with all the NDV strains. All strains showed the first $\mathrm{K}_{d}{ }^{\text {rel }}\left(\mathrm{K}_{d 1}{ }^{r e l}\right)$ values in picomolar range, whereby the binding affinity of velogens ranged from 2.4 to $2.8 \mathrm{pM}$, while affinities for the mesogens and lentogens varied from 3.3 to $4.5 \mathrm{pM}$ (Table 1). As for the second $\mathrm{K}_{d}$ rel $\left(\mathrm{K}_{d 2}{ }^{r e l}\right)$, no particular profile was obtained, and binding affinities for all strains were in the nanomolar range.

\section{NDV Pathotyping}

For pathotyping, the amount of NDV strains coated on the wells ranged from 2-50 HAU. Virus as low as $2 \mathrm{HAU}$ were detected for the velogenic strains. For the mesogenic and lentogenic strains, at least $10 \mathrm{HAU}$ were essential. When the TLTTKLY phage was replaced by a wild-type M13 that did not carry any fusion peptide, and the absorbance values were found lower than the cut-off value (data not shown). The graph (Figure 3) displays a profile whereby two clusters were obvious. The first is represented by only the velogenic strains and the second comprises the mesogenic and lentogenic strains. This observation has been made consistently over many experiments using freshly prepared phage and NDV strains (15). A correlation was observed between the binding affinities obtained in the equilibrium binding experiment and the absorbance profiles in the ELISA experiment for the different pathotypes of NDV strains. The $\mathrm{K}_{d l}{ }^{\text {rel }}$ values and the profiles of the ELISA experiment can be grouped into two categories. Based on the $\mathrm{K}_{d l}$ rel values, the velogenic strains form the first group, while the mesogens and lentogens form the second. This is exactly similar to that of the pathotyping results described above, whereby the velogens formed the first group and were more readily detectable compared to the second group comprising of mesogenic and lentogenic strains.

\section{DISCUSSION}

Identification of a disease in early stages is a more effective way of disease control. There are many assays established for the detection and pathotyping of NDV, most of which involve a combination of molecular techniques. In this study, using the TLTTKLY phage, it was demonstrated that the pathotypes of NDV could be differentiated into two groups. The first cluster was represented by only the velogenic strains, while the mesogenic and lentogenic strains formed the second cluster. Furthermore, the TLTTKLYbearing phage could detect the virus at as low as 2 HA units. These results suggest that the TLTTKLY phage is a sensitive diagnostic reagent for the detection of NDV. This is because the binding affinity of a peptide as a diagnostic reagent is probably less stringent than as therapeutics. For instance, for immunohistochemical procedures, it is probably not necessary to have a binding affinity of $10^{8} \mathrm{M}^{-1}$, providing specificity is reasonably good (19). In this case, the TLTTKLY-carrying phage, which has exhibited higher affinity $\left(\mathrm{K}_{d l}{ }^{r e l}=2.8 \mathrm{pM}\right)$, seems to be far superior as a diagnostic or pathotyping reagent for NDV.

The data of the equilibrium-binding assay showed that the TLTTKLY phage displayed two widely differing affinities with all the NDV strains. This could be due to the fact that the system has two or more classes of binding sites with different affinities (20), and this is a more complex association than that of phage-antibody and phage-hepatitis $\mathrm{B}$ core antigen ( $\mathrm{HBcAg}$ ) interactions, which gave rise to only one binding affinity $(21,22)$. Display of two dissociation constants for all the $12 \mathrm{NDV}$ strains tested suggests that this phage probably recognizes two different docking sites on NDV strains with a varying degree of affinity. In an earlier study, we showed that the peptide TLTTKLY, either in linear or cyclic form, inhibited NDV propagation in the allantoic fluid of embryonated chicken eggs (12). These peptides did not inhibit the HA and NA activities, but did inhibit the hemolytic activity, suggesting that the peptides interact with the F activity site. However, the peptides may bind to other parts of the $\mathrm{HN}$ or F glycoproteins and change the F activity site (12).

The $\mathrm{K}_{d l}{ }^{\text {rel }}$ values showed a profile where the velogenic strains can be distinguished from the mesogenic and lentogenic strains. This correlates with the two different absorbance profiles in the ELISA experiment. However, the $\mathrm{K}_{d 2}{ }^{r e l}$ values do not reveal any particular profile that can be used to distinguish these pathotypes. Two mesogens, 2641/91 P2 (0.98 nM) and 5953/89 P3 (0.56 $\mathrm{nM})$ had relatively high $\mathrm{K}_{d 2}{ }^{\text {rel }}$ values compared to the velogens, especially AF2240 (1.4 nM) and 01/TM (1.11 $\mathrm{nM})$. The values obtained here are regarded as relative values because of the complication resulting from the presence of up to five copies of the gpIII fusion protein of the M13 filamentous phage. As a result, a single phage particle could bind to the target via multiple interactions, thus enhancing the affinity (18). All the NDV strains were assayed with the same phage, so that the effect of the multiple copies of peptide should be the same for each one of the strains, and therefore, the values are affected to a similar degree, which in comparison is valid (23). Likewise, even with lowaffinity interactions at each site, multivalent binding leads to high avidity and tenacious adherence of the phage during washing (24). In this view, it is probable that the $\mathrm{K}_{d 2}{ }^{r e l}$ values obtained for the interaction between the TLTTKLY phage and the various NDV strains were due to these phenomena.

This study illustrates the potential of using displayed peptide ligands as a pathotyping reagent, and to the best of our knowledge, there is currently no information available on the use of phage carrying a short peptide in pathotyping of other viruses. However, single-chain $\mathrm{Fv}(\mathrm{scFv})$ fragments against the motif ${ }^{112} \mathrm{RRQ}^{114}$ present at the $\mathrm{F}_{2} \mathrm{C}$-terminal end of many virulent NDV isolates were generated for differentiating virulent and avirulent NDV strains (25). Although this system was specific, the sensitivity was quite dependent on the amino acids present at position 110 of the $\mathrm{F}$ protein, just preceding the cleavage site. Furthermore, this $\mathrm{scFv}$ phage cannot differentiate between the velogenic and mesogenic strains, as both of these strains are virulent. Differentiating these virulent strains is of utmost importance in times of an outbreak, as it reveals whether the birds have previously been vaccinated or not. 
The production and purification of the fusion phage are easier and less expensive compared to monoclonal antibodies, thus the phage has the potential to be further developed into a diagnostic reagent for NDV pathotyping based upon different affinity constants. The preferred assay format is a double sandwich method, in which the wells are coated with the phage and unpurified NDV is allowed to react with the immobilized phage. In addition, further work has to be carried out to study the stability of the phage, especially its fusion peptide during storage, and also to manipulate its genes to produce fusions to reporter molecules to accelerate the detection method.

\section{ACKNOWLEDGMENTS}

We thank Dr. Abdul Rahman Omar from the Faculty of Veterinary Medicine, Universiti Putra Malaysia for providing us NDV strains 00/IKS, 01/TM, and 00/C. This study was supported by Intensification of Research in Priority Areas (IRPA) grants 01-0204-03-BTK/ER/006 and 50205-99-34 of the Ministry of Science, Technology, and the Environment, Malaysia.

\section{REFERENCES}

1.Alexander, D.J. 2001. Newcastle disease. Br. Poult. Sci. 42:5-22.

2.Yusoff, K. and W.S. Tan. 2001. Newcastle disease virus: macromolecules and opportunities. Avian Pathol. 30:439-455.

3.McGinnes, L.W., K. Gravel, and T.G. Morrison. 2002. Newcastle disease virus HN protein alters the conformation of the $\mathrm{F}$ protein at cell surfaces. J. Virol. 76:12622-12633.

4.Stauber, N., K. Brechtbukl, L. Bruckner, and M.A. Hofmann. 1995. Detection of Newcastle disease virus in poultry vaccines using the polymerase chain reaction and direct sequencing of amplified cDNA. Vaccine 13:360-364.

5.Collins, M.S., J.B. Bashiruddin, and D.J. Alexander. 1993. Deduced amino acid sequences at the fusion protein cleavage site of Newcastle disease viruses showing variation in antigenicity and pathogenicity. Arch. Virol. 128:363-370

6.Seal, B.S., D.J. King, and J.D. Bennett. 1995. Characterization of Newcastle disease virus isolates by reverse transcription PCR coupled to direct nucleotide sequencing and development of sequence database for pathotype prediction and molecular epidemiology analysis. J. Clin. Microbiol. 33:2624-2630.

7.Wang, Z., F.T. Vreede, J.O. Mitchell, and
G.J. Viljoen. 2001. Rapid detection and differentiation of Newcastle disease virus isolates by a triple one-step RT-PCR. Onderstepoort J. Vet. Res. 68:131-134.

8.Aldous, E.W., M.S. Collins, A. McGoldrick, and D.J. Alexander. 2001. Rapid pathotyping of Newcastle disease virus (NDV) using fluorogenic probes in a PCR assay. Vet. Microbiol. 80:201-212.

9.Gorman, J.J., A.N. Hodder, P.W. Selleck, and E. Hansson. 1992. Antipeptide antibodies for analysis of pathotype-specific variations in cleavage activation of the membrane glycoprotein precursors of Newcastle disease virus isolates in cultured cells. J. Virol. Methods 37:55-70.

10.Hodder, A.N., P.W. Selleck, J.R. White, and J.J. Gorman. 1993. Analysis of pathotypesspecific structural features and cleavage activation of Newcastle disease virus membrane glycoproteins using antipeptide antibodies. J. Gen. Virol. 74:1081-1091.

11.Scanlon, D.B., G.L. Corino, B.J. Shiell, A.J., Della-Porta, R.J. Manvell, D.J. Alexander, A.N. Hodder, and J.J. Gorman. 1999. Pathotyping isolates of Newcastle disease virus using antipeptide antibodies to pathotype-specific regions of their fusion and haemagglutinin-neuraminidase proteins. Arch. Virol. 144:55-72.

12.Ramanujam, P., W.S. Tan, S. Nathan, and K. Yusoff. 2002. Novel peptides that inhibit the propagation of Newcastle disease virus. Arch. Virol. 147:981-993.

13.Gorman, J.J., A. Nestorowicz, S.J. Mitchell, G.L. Corino, and P.W. Selleck. 1988. Characterization of the sites of proteolytic activation of Newcastle disease virus membrane glycoprotein precursors. J. Biol. Chem. 263: 12522-12531.

14.Salih, O., A. R. Omar, A.M. Ali, and K. Yusoff. 2000. Nucleotide sequence analysis of the $\mathrm{F}$ protein gene of a Malaysian velogenic NDV strain AF2240. J. Biochem. Mol. Biol. Biophys. 4:51-57.

15.Ramanujam, P. 2003. Peptide ligands that interact with Newcastle disease virus: selection, characterization and application. Ph.D. thesis, Universiti Putra Malaysia.

16.Bradford, M.M. 1976. A rapid and sensitive method for the quantitation of microgram quantities of protein utilizing the principle of protein-dye binding. Anal. Biochem. 72: 248-254.

17.Alexander, D.J. 1988. Newcastle disease diagnosis, p. 147-160. In D.J. Alexander (Ed.), Newcastle Disease. Kluwer Academic Publishers, London.

18.Dyson, M.R., V. Germaschewski, and K. Murray. 1995. Direct measurement via phage titre of the dissociation constant in solution of fusion phage-substrate complexes. Nucleic Acids Res. 23:1531-1535.

19.Burton, D.R. 1995. Phage display. Immunotechnology 1:87-94.

20.Tan, W.S., M.R. Dyson, and K. Murray. 1999. Two distinct segments of the hepatitis $B$ virus surface antigen contribute synergistically to its association with the viral core particles. J. Mol. Biol. 286:797-808.

21.Ho, K.L., K. Yusoff, H.F. Seow, and W.S. Tan. 2003. Selection of high affinity ligands to hepatitis B core antigen from a phage-displayed cyclic peptide library. J. Med Virol. 69: 27-32.

22.Tan, W.S., M.R. Dyson, and K. Murray. 2003. Hepatitis B virus core antigen: enhancement of its production in Escherichia coli, and interaction of the core particles with the viral surface antigen. Biol. Chem. 384:363-371.

23.Tan, W.S. and M.R. Dyson. 2000. A simple method to determine the binding affinities of proteins expressed in rabbit reticulocyte lysates. J. Biochem. Mol. Biol. Biophys. 4: 41-49.

24.Cwirla, S.E., E.A. Peters, R.W. Barrett, and W.J Dower. 1990. Peptides on phage: a vast library of peptides for identifying ligands. Proc. Natl. Acad. Sci. USA 87:6378-6382.

25.Li, Y., M.S. Collins, G.C. Whotelam, and D.J. Alexander. 2002. Rapid pathotyping of Newcastle disease virus using a single-chain Fv displayed on phage against the C-terminal end of the F2 polypeptide. Arch. Virol. 147: 2025-2037.

Received 30 July 2003; accepted 3 November 2003.

\section{Address correspondence to:}

Khatijah Yusoff

Department of Biochemistry and Microbiology

Faculty of Science and Environmental Studies

Universiti Putra Malaysia

UPM 43400 Serdang

Selangor, Malaysia

e-mail: khatijah@fsas.upm.edu.my 